\title{
Transcriptional regulation of flavonoid biosynthesis in nectarine (Prunus persica) by a set of R2R3 MYB transcription factors
}

\author{
Daniela Ravaglia ${ }^{1}$, Richard V Espley², Rebecca A Henry-Kirk², Carlo Andreotti ${ }^{3}$, Vanina Ziosi ${ }^{1}$, Roger P Hellens², \\ Guglielmo Costa ${ }^{1}$ and Andrew C Allan $2,4^{*}$
}

\begin{abstract}
Background: Flavonoids such as anthocyanins, flavonols and proanthocyanidins, play a central role in fruit colour, flavour and health attributes. In peach and nectarine (Prunus persica) these compounds vary during fruit growth and ripening. Flavonoids are produced by a well studied pathway which is transcriptionally regulated by members of the MYB and bHLH transcription factor families. We have isolated nectarine flavonoid regulating genes and examined their expression patterns, which suggests a critical role in the regulation of flavonoid biosynthesis.

Results: In nectarine, expression of the genes encoding enzymes of the flavonoid pathway correlated with the concentration of proanthocyanidins, which strongly increases at mid-development. In contrast, the only gene which showed a similar pattern to anthocyanin concentration was UDP-glucose-flavonoid-3-O-glucosyltransferase (UFGT), which was high at the beginning and end of fruit growth, remaining low during the other developmental stages. Expression of flavonol synthase (FLS1) correlated with flavonol levels, both temporally and in a tissue specific manner. The pattern of UFGT gene expression may be explained by the involvement of different transcription factors, which up-regulate flavonoid biosynthesis (MYB10, MYB123, and bHLH3), or repress (MYB111 and MYB16) the transcription of the biosynthetic genes. The expression of a potential proanthocyanidin-regulating transcription factor, MYBPA1, corresponded with proanthocyanidin levels. Functional assays of these transcription factors were used to test the specificity for flavonoid regulation.
\end{abstract}

Conclusions: MYB10 positively regulates the promoters of UFGT and dihydroflavonol 4-reductase (DFR) but not leucoanthocyanidin reductase (LAR). In contrast, MYBPA1 trans-activates the promoters of DFR and LAR, but not UFGT. This suggests exclusive roles of anthocyanin regulation by MYB10 and proanthocyanidin regulation by MYBPA1. Further, these transcription factors appeared to be responsive to both developmental and environmental stimuli.

Keywords: Anthocyanin, Transcriptional regulation, MYB, Peach, Nectarine, Prunus persica, Light

\section{Background}

Anthocyanins, flavonols and flavan-3-ols belong to the group of the ubiquitous secondary metabolites known as flavonoids. They represent the main classes of phenolic compounds in fruit [1-3] and play a central role as determinants of fruit quality. The accumulation of anthocyanin pigments in fruit provides essential cultivar differentiation

\footnotetext{
* Correspondence: Andrew.Allan@plantandfood.co.nz

${ }^{2}$ The New Zealand Institute for Plant and Food Research (PFR), Private Bag 92 169, Auckland, New Zealand

${ }^{4}$ School of Biological Sciences, University of Auckland, Private Bag 92019 , Auckland, New Zealand

Full list of author information is available at the end of the article
}

for consumers and represents an important factor for marketability, while the flavan-3-ols (precursors of the proanthocyanidins) can be a major influence on fruit flavour. Proanthocyanidins impart astringency to fresh fruits, fruit juices and wine, oxidise to form brown pigments in seeds and other tissues and may act as feeding deterrents in reproductive tissues and developing fruits $[4,5]$. Anthocyanins, flavonols and flavan-3-ols influence the health attributes of our fruit thanks to their natural antioxidant capacity [6]. Several studies correlated the intake of these compounds with the lower incidences of certain chronic

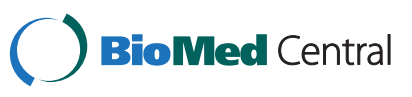


diseases such as cancers, cardiovascular, and neurodegenerative disease [7-11].

Peach is an important global Rosaceous fruit with world production of over 18 million tonnes in 2009, concentrated in centres such as China, Italy, Spain and USA (http://www.fao.org). Peach and nectarine (both Prunus persica) are characterized by a wide range of different cultivars, with their health attributes and colour of both skin and flesh being important factors for consumer choice. Red colour in peach fruit has been the object of most breeding programs. In particular, high levels of red colouration have been sought in cultivars for the fresh market. In contrast, reduced pigment content in any part of the fruit has been the aim of most breeding programs for the canning industry because of the possibility of staining in the processed product. The primary pigment responsible for red colouration in peaches and nectarines is cyanidin and, in particular, cyanidin 3glucoside, one of the most common anthocyanin pigments in fruit $[12,13]$. The main flavan-3-ol identified in peach is catechin, while the flavonols are dominated by three glycosylated quercetins (quercetin 3-galactoside, quercetin 3-glucoside and quercetin 3-rutinoside) [12,13].

Anthocyanins, flavonols and flavan-3-ols are synthesized via the flavonoid pathway, whose genetics and biochemistry have been well characterized in several plant species $[14,15]$. The pathway consists of several steps, which are common to the synthesis of different flavonoids, and branch steps, which are more specific for each type of flavonoid (Figure 1). The flavonoid pathway appears to be mainly regulated at the level of transcription of genes encoding the enzymes of the pathway [15]. Several transcription factors (TFs) have been isolated in a diverse group of plants [16-20] which control this transcription. In particular, interacting R2R3-MYB and bHLH type TFs, form a complex with WD40 proteins (termed the MBW complex), to activate the anthocyanin and proanthocyanidin biosynthetic genes. The MBW complex usually regulates groups of flavonoid biosynthetic genes, which vary between species [17]. This regulation is via specific binding to motifs in the promoters of the pathway genes [21-23].

Several studies conducted on apple (Malus $\times$ domestica) confirmed that all the biosynthetic genes leading to the anthocyanin synthesis are co-ordinately regulated [24-26]. The R2R3-MYB and bHLH TFs responsible for the anthocyanin accumulation have been isolated and characterized [27-30]. In contrast, the grape R2R3-MYB TF VvMYBA, which regulates anthocyanin biosynthesis, appears to activate only the UDP-glucose:flavonoid-3-O-glycosyltranferase (UFGT) gene. This plays a key role in colour development in grape skin, distinguishing white and red grapes [31,32]. A peach TF, PpMYB10, has been shown to activate both the tobacco anthocyanin pathway, and the Arabidopsis

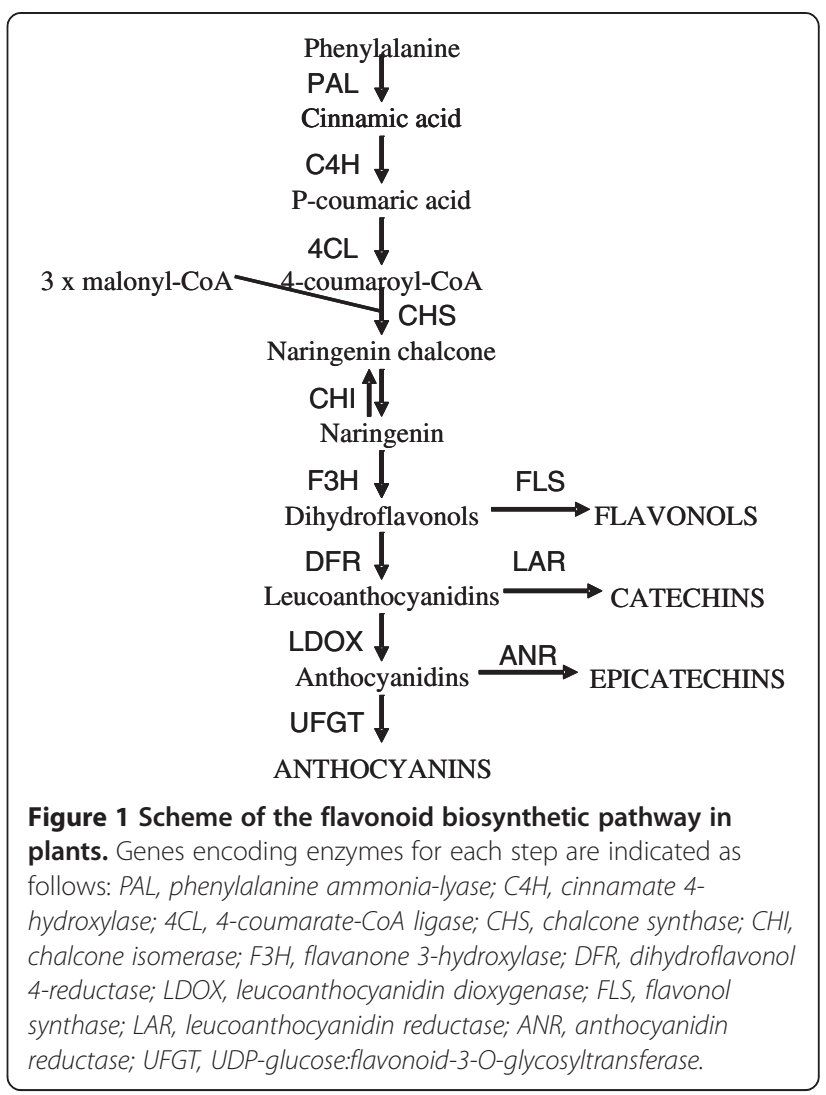

dihydroflavonol 4-reductase (DFR) promoter, when assayed transiently [33].

Flavonols are synthesized from the dihydroflavonols by flavonol synthase (FLS) enzymes (Figure 1). In peach the major flavonols are quercetin derivatives [13]. In Arabidopsis, the regulation of flavonol biosynthesis has been investigated. Three closely related MYBs AtMYB11, AtMYB12 and AtMYB111 (also known as PFG1-PFG3, for Production of Flavonol Glucosides) regulate AtFLS1 and other steps $[34,35]$. In maize, the orthologue of FLS is regulated by UV exposure via activation of maize's MYB/bHLH orthologous transcription factors [36]. In grape VvMYBF1 regulates grape FLS in a light dependent manner [37].

The genes encoding enzymes specific for the proanthocyanidins (ANR: anthocyanidin reductase; LAR: leucoanthocyanidin reductase) have been isolated from, amongst others, apple and grape [38-40]. Takos et al., (2006) [39] showed that the proanthocyanidin biosynthetic genes in apple appear to be differentially regulated in comparison to other flavonoid biosynthetic genes. Studies in grape report the characterization of at least four MYB TFs (VvMYB5a, VvMYB5b, VvMYBPA1 and VvMYBPA2) that regulate steps in the flavonoid pathway, which could affect the accumulation of the proanthocyanidins in leaves, flowers and early in berry development, before the véraison stage. These MYBs induce the expression of both the proanthocyanidin branch genes 
and several of the general flavonoid pathway genes, but not UFGT [41].

Adding to the complexity of the transcriptional control of flavonoid biosynthesis is a group of MYB TFs which act as repressors of the pathway $[42,43]$. In particular, the regulatory activity of an R3-MYB TF called AtMYBL2 (At1g71030) has been characterized in Arabidopsis, where it plays a crucial role in the repression of anthocyanin biosynthesis. A model has been proposed whereby AtMYBL2 interferes with the activity of the MBW complex $[44,45]$. In apple [46] and strawberry [42] MYB repressors have been examined and shown to increase with fruit maturity, even though anthocyanin levels are increasing, suggesting competition with MYB activators.

Most of the genes encoding enzymes leading to the anthocyanin synthesis in peach fruit have been studied $[47,48]$. Crosses of red and non-red peaches suggest that a major gene controls peach colour $[49,50]$. However, there is no data about either the flavonol $(F L S)$ or flavan-3-ol specific genes $(A N R$ and $L A R)$ or the regulation of the flavonoid metabolism in this plant. In this study we report the transcript levels of the main biosynthetic genes leading to the synthesis of anthocyanins, flavonols, and flavan-3-ols in 'Stark Red Gold' nectarines during fruit growth, ripening, and environmental manipulation. We also identified key TFs, which appear to play a crucial role in the regulation of the flavonoid pathway in peach/nectarine acting to activate (MYB10, MYB123, bHLH3, WD40 and MYBPA1) or potentially repress (MYB16 and MYB111). Members of these transcriptional complexes activated the peach UFGT and $L A R 1$ promoters, and were responsive to both developmental and environmental stimuli.

\section{Results}

Anthocyanin and flavan-3-ol accumulation during fruit development and ripening

The development series of 'Stark Red Gold' nectarine, and the anthocyanin and flavan-3-ol accumulation in fruit tissues, are shown in Figure 2. During fruit growth there were two peaks of anthocyanin accumulation in peel: one early in development (50 DAFB) and the other at the end of fruit growth (135 DAFB; Figure 2B). Very low concentrations of anthocyanin were observed for fruit in the middle stages of development. The anthocyanins detected were either cyanidin 3-glucoside or cyanidin 3-rutinoside as seen in previous studies [13], with cyanidin 3-rutinoside present only at the beginning of fruit development (50 DAFB) at low concentration. In contrast, the concentration of proanthocyanidins or flavan-3-ols, in both peel and flesh, was low at the beginning of fruit development (50 DAFB), strongly increased at mid-development, and finally decreased again during ripening (135 DAFB; Figure 2C). Flavonols (mainly quercetin-3-galactoside with some

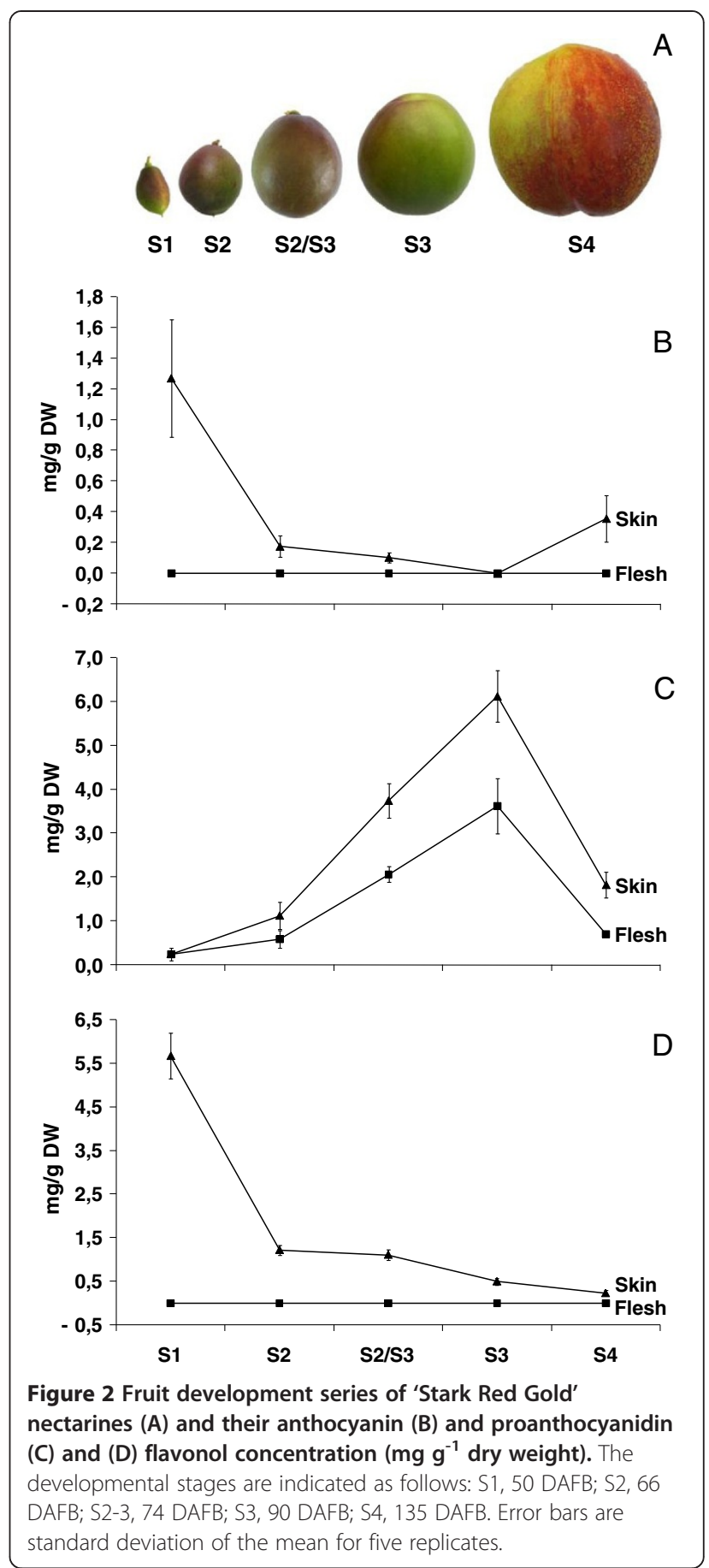

quercetin-3-glucoside and quercetin-3-rutinoside) showed a similar pattern to anthocyanin, being skin located, but showed no increase at maturity (Figure 2D).

No anthocyanin was detected by HPLC analysis in the flesh at any developmental stage. However, a few red stripes were observed near the stone during the sampling of the ripe fruit (S4). This suggests that this cultivar can accumulate anthocyanins in flesh, but in the 
Figure 3 Relative expression profiling of biosynthetic genes for main pathway flavonoid and anthocyanin synthesis in skin and flesh of 'Stark Red Gold' nectarines. The developmental stages are indicated as follows: S1, 50 DAFB; S2, 66 DAFB; S2-3, 74 DAFB; S3, 90 DAFB; S4, 135 DAFB. PpActin used as reference gene. Error bars are standard error of the mean for three replicate reactions.

sampled tissue concentrations were too low for detection by HPLC analysis.

\section{RNA expression profile of the flavonoid biosynthetic enzymes in nectarine fruit}

The sequences of nine putative flavonoid biosynthetic genes were identified in the publicly available peach nucleotide and EST databases. For each biosynthetic gene, we selected the peach sequence expressed in fruit which showed the highest homology in BLAST searches to the Malus $\times$ domestica corresponding protein. The levels of transcription of these nine selected flavonoid biosynthetic genes were determined, in both peel and flesh of 'Stark Red Gold' nectarines, during fruit development and ripening using quantitative PCR (qPCR, Figures 3 and 4).

The early biosynthetic genes common to both anthocyanin and flavan-3-ol biosynthesis within the phenylpropanoid pathway (CHS, CHI, F3H, DFR) and the late biosynthetic steps specific for proanthocyanidins and anthocyanin (LDOX and UFGT) showed contrasting patterns (Figure 3). The transcript levels of most of these genes were very low at the beginning of fruit development (50 DAFB), strongly increased up to 74 DAFB and then decreased again through to fruit maturation (135 DAFB) in both peel and flesh. A slightly different expression profile was recorded for the $L D O X$ gene, which encodes the enzyme that is the last common step shared by anthocyanin and flavan-3-ol biosynthesis. Its transcript level in both peel and flesh was low at the beginning of fruit development, increased from 66 DAFB up to 74 DAFB, and then remained high throughout fruit maturation (Figure 3).

In contrast, the expression profile of the UFGT gene was significantly different to all the other biosynthetic genes examined (Figure 3). Its transcript in peel was most abundant at the beginning (50 DAFB) and end (135 DAFB) of fruit growth, remaining low throughout the middle of development (from 66 to 90 DAFB). UFGT transcript was detected also in flesh, but only in the last ripe fruit time point (135 DAFB). This pattern of expression correlated with the pattern of anthocyanin accumulation in fruit, but was not statistically significant (Additional file 1: Table S1).

Transcript levels of FLS were well correlated with the accumulation of flavonols (Figure 4). FLS showed no flesh expression suggesting tight skin-specific regulation of the gene. $L A R$ and $A N R$ showed very similar patterns of expression to each other and were expressed in both skin 


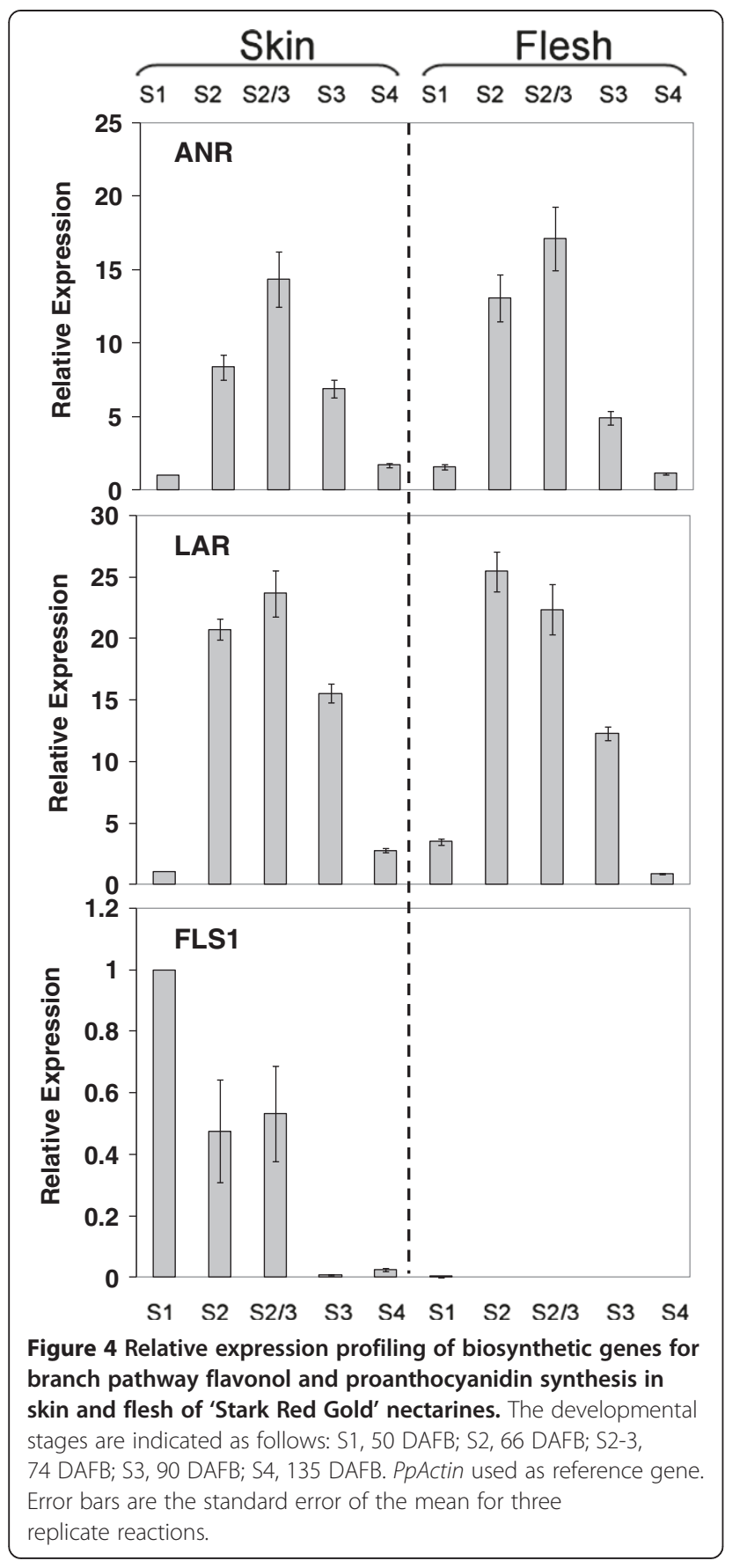

and flesh. This followed the profile of proanthocyanidin levels (Figure 2) which is present in both skin and flesh.

\section{Quantitative PCR expression analysis of putative transcription factor genes in nectarine fruit}

Candidate genes encoding TFs involved in the regulation of the flavonoid biosynthesis were selected within Prunus sequences in the Genome Database for Rosaceae (http://www.rosaceae.org) or by homology with Malus × domestica and Arabidopsis TFs. In particular, the sequences showing the highest homology to members of the anthocyanin regulating transcriptional complex (MBW) and polyphenolic-related MYBs were selected for primer design. Lead candidates for expression analysis were peach $M Y B 10$ and $b H L H 3$, because of their high homology to the activators of anthocyanin synthesis in apple (MdMYB10 and $M d b H L H 3)$. A candidate gene showing high BLAST homology to the WD40 TTG1 (At5g24520) protein was found (ACQ65867). R2R3 MYBs with homology to $V v M Y B F 1$, $V v M Y B 5 a$, AtMYB123 (TT2), VvMYBPA2 and VvMYBPA1 were selected by best blast match. Potential repressor MYBs, peach MYB111 and MYB16 showed homology to apple repressors [46]. A phylogeny of full length predicted proteins was generated (Figure 5).

The expression profiles of candidate TF genes, MYB10, bHLH3 and WD40, were investigated in both peel and flesh of 'Stark Red Gold' nectarines at different developmental stages (Figure 6). Transcript of MYB10 was detectable only in fruit peel, where its level was highest from 66 to 90 DAFB and lower at the beginning (50 DAFB) and end of fruit growth (135 DAFB). Two notable features of the MYB10 profile were the absence at all stages of any flesh MYB10 transcript and the lower levels of transcript in mature skin at a stage when UFGT and anthocyanin accumulation is at its maximum. Expression profiles of the bHLH3 and WD4O genes in both peel and flesh followed the pattern of most of the genes encoding biosynthetic enzymes, with a maximum at 90 DAFB in fruit development. Its transcript was also well expressed in ripe fruit (135 DAFB), as was observed for the $L D O X$ and $U F G T$ genes.

The potential proanthocyanidin regulating MYB, MYBPA1, was expressed in both peel and flesh with transcript level correlating with the profiles of flavan-3-ols (Figure 7). In ripe fruit, where $L D O X$ and $U F G T$ were most up-regulated and $L A R$ and ANR down-regulated, the transcription of MYBPA1 was barely detectable. The other potential regulator of proanthocyanidins, PPMYBPA2, showed no expression in fruit (data not shown). MYB15 and MYB123, both good candidates for flavonol regulation, show both skin-specificity and a decline at maturity. This correlates with the flavonol levels which are restricted to skin, early in development (Additional file 1: Table S1).

The potential repressor MYBs, MYB111 and MYB16, were expressed in both peel and flesh with transcript level correlating well with the profiles of most of the biosynthetic genes up to 90 DAFB (Figure 8). However, in ripe fruit, where $L D O X$ and UFGT were most upregulated, and anthocyanins are accumulated, the transcription of MYB16 was barely detectable.

\section{Differential activation of nectarine biosynthetic gene promoters by MYB10 and MYBPA1}

To test the role of MYB10 and MYBPA1 on the activation of nectarine/peach flavonoid synthesis, the promoters of 


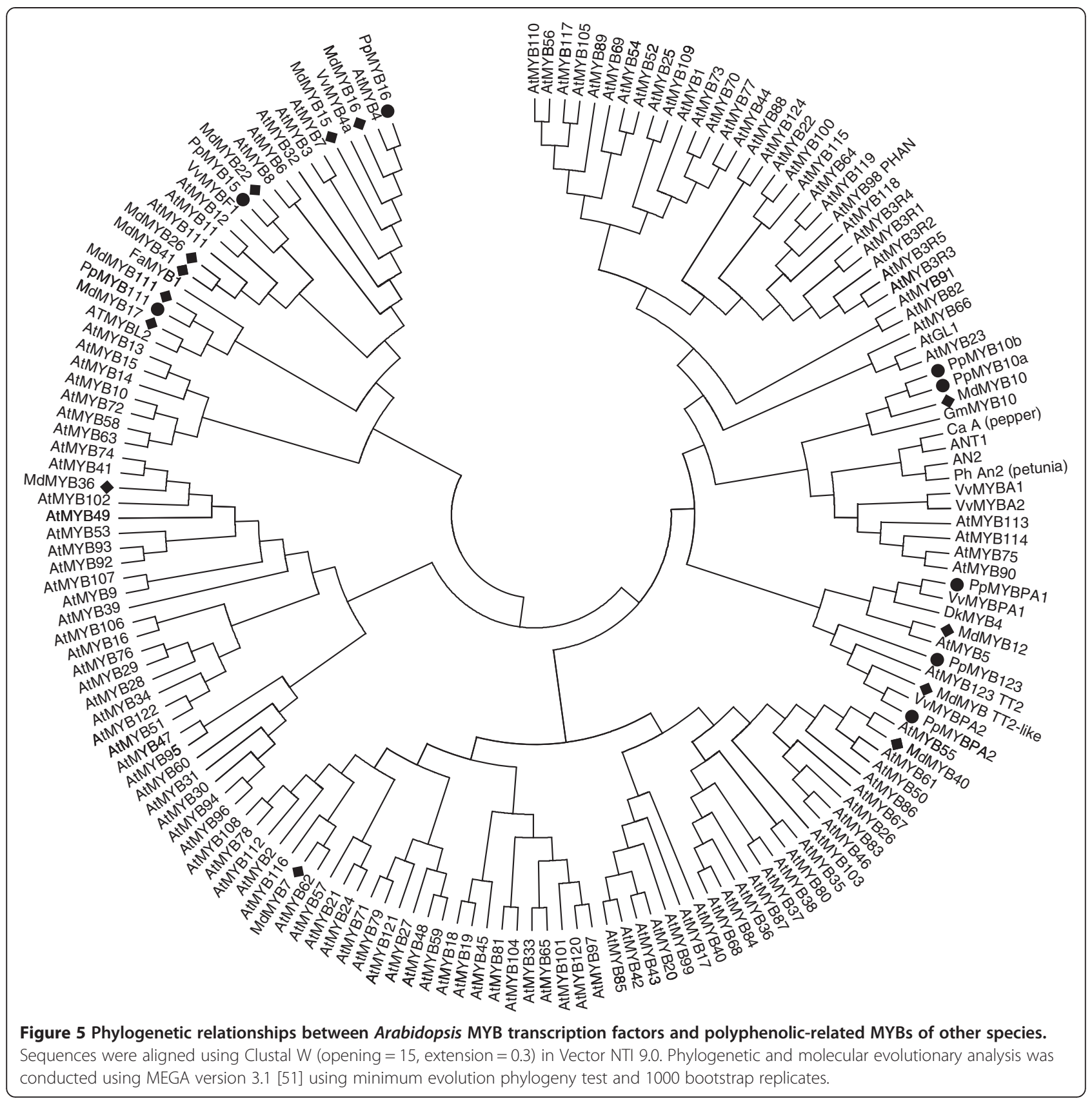

peach UFGT, DFR and $L A R$ were isolated and cloned into the dual luciferase assay system [52]. N. benthamiana was transiently transformed by infiltration with an Agrobacterium suspension containing a luciferase reporter construct with fragments of each promoter and a separate Agrobacterium suspension containing 35S:PpMYB10, 35S:PpMYBPA1 and 35S:PpbHLH3. While the control infiltration (promoter-LUC fusion alone) showed only minimal activity, co-infiltration of MYB10 with 35S:PpbHLH3 showed a large rise in UFGT and DFR promoter activity with a ratio of LUC to REN of 2.5 or 2.0 respectively (Figure 9). Infiltration of the reporter with $b H L H 3$ or MYB10 alone resulted in low activation. In contrast, MYBPA1 had little activity against the UFGT promoter, and good activity in promoting LUC expression if driven by the $D F R$ and $L A R$ promoters. This activation required bHLH3. MYB10 showed little ability to activate the $L A R$ promoter.

\section{Light-induced accumulation of anthocyanin in nectarine} fruit correlates with the expression of the MYB-bHLH TFs Mature fruit were harvested from shaded areas of the tree, which showed low levels of colour. These fruit were either given a light treatment (UV + white light) or covered for 72 hours. Treatment with artificial light was 


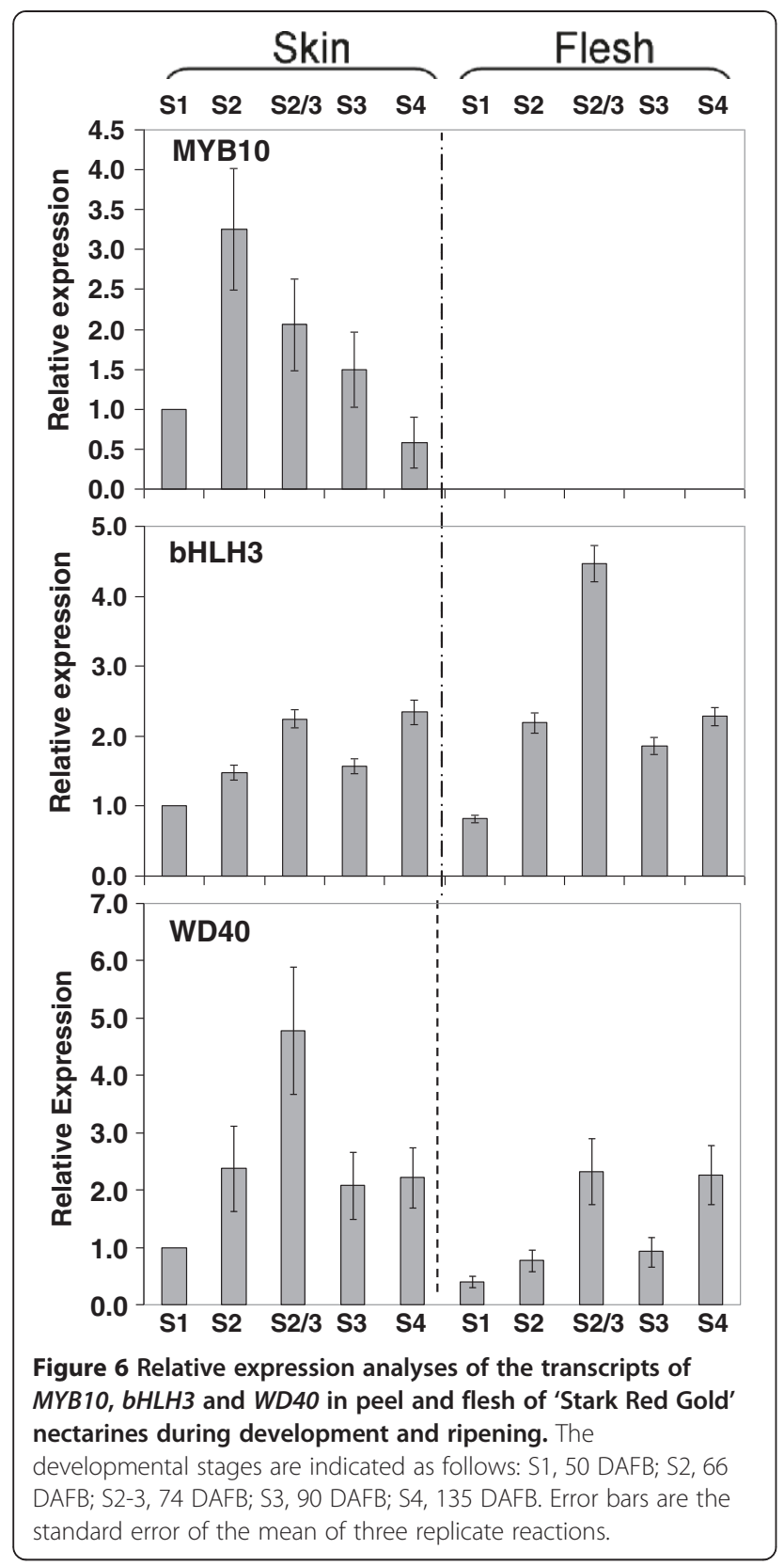

able to strongly increase the red colouration of the peel (Figure 10A), inducing the biosynthesis and accumulation of anthocyanins. The other polyphenolic compounds, such as flavonols and proanthocyanidins showed no significant increase with UV + white light (data not shown). The influence of the light treatment on the levels of expression of DFR, UFGT, MYB10, PpbHLH3 and WD40 genes was investigated by qPCR analyses (Figure 10B). The transcripts of all the assayed genes, except the WD40, were elevated in the bright red peel of the fruit exposed to the light treatment, in comparison to low levels of transcript in the yellow peel of the fruit at harvest time and after 72 hours in the dark.

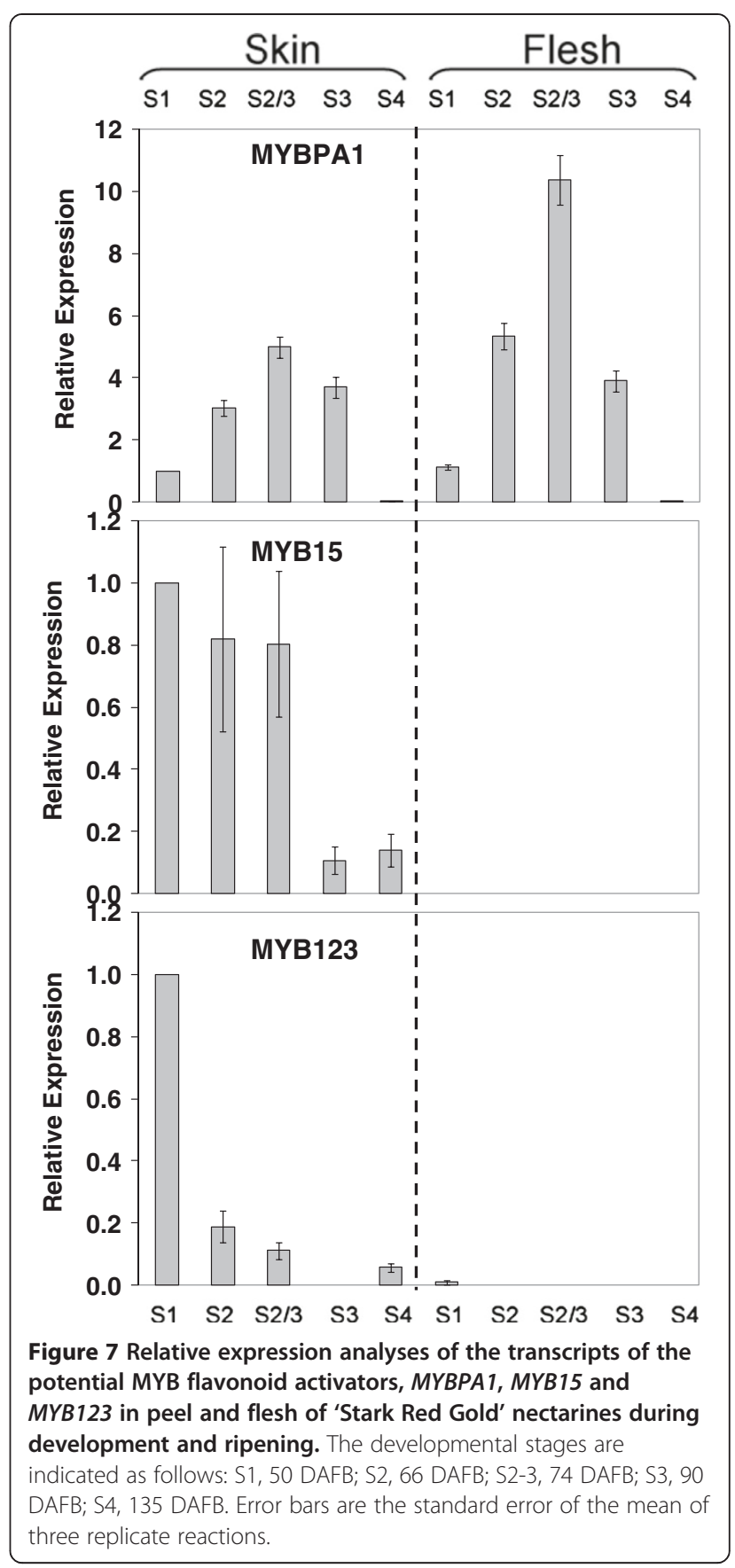

The transcript of the DFR and UFGT genes were respectively eightfold and fourfold more abundant in the light-exposed fruit than in those just harvested or kept in the dark, correlating well with the fruit peel colour. Transcripts of MYB10, and $b H L H 3$ genes were induced by the light treatment. In particular, the expression of the MYB10 gene was the most strongly responsive to the light, showing a 30-fold elevation in the lightexposed fruit compared to the fruit at harvest time. Transcript level of MYB10 declined to not detectable levels in the fruit kept in the dark. 


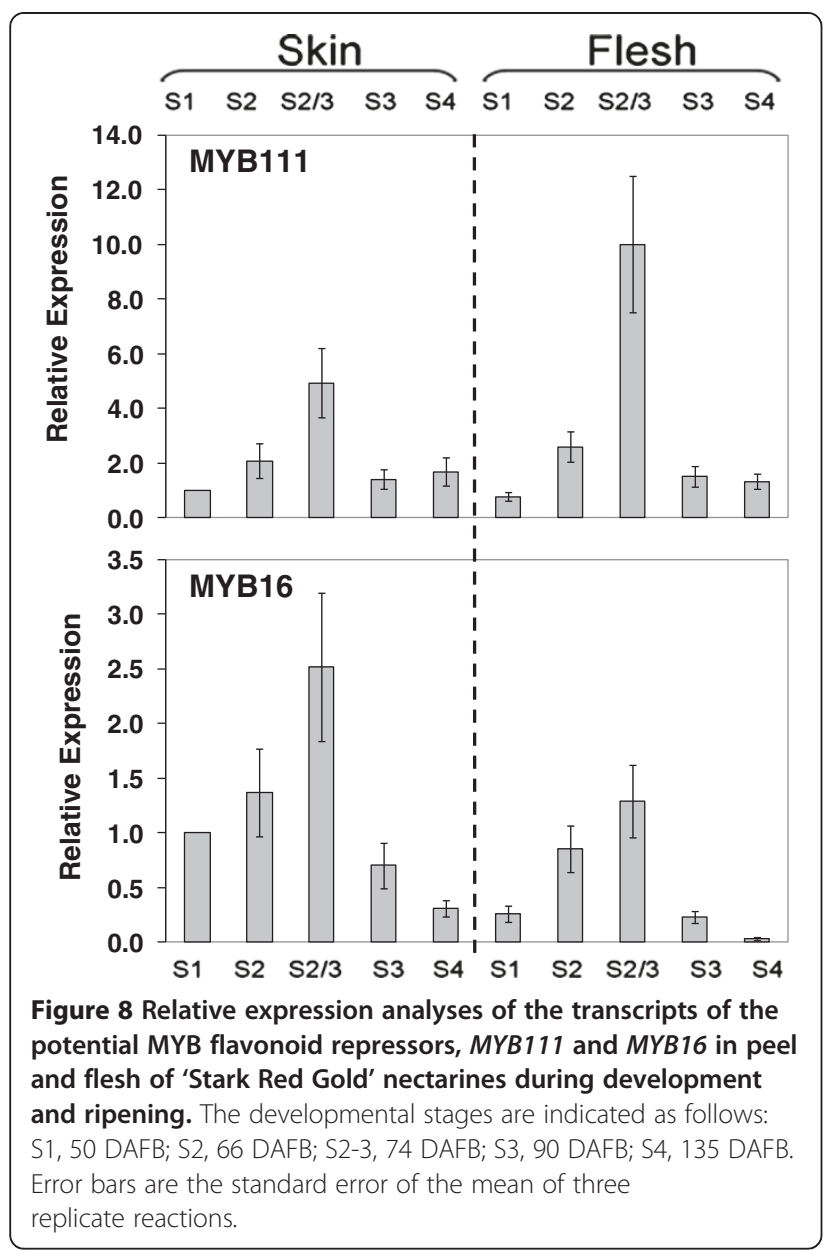

Other flavonoid related genes were also analysed (Additional file 2: Figure S1). Only FLS showed a slight stimulation by UV/light exposure, while the regulatory MYBs MYBPA1, MYB111 and MYB15 were also upregulated by the treatment.

\section{Discussion}

Regulation of anthocyanin and flavan-3-ol biosynthesis in nectarine/peach

The regulation of anthocyanin and flavan-3-ol biosynthesis has been studied in a diverse range of crops such as apple [27-30,39,40], grape [32,53-56], strawberry [33,42], tomato $[57,58]$, and pepper [59]. This is due to their influence on fruit and vegetable colour, flavour and health attributes. However, there is apparently no data about the transcriptional regulation of the flavonoid metabolism in peach and nectarine (Prunus persica).

Our results showed that anthocyanins and flavan-3-ols have different patterns of accumulation in 'Stark Red Gold' nectarines during development, as observed previously [12]. Flavan-3-ols mainly accumulated at midseason in both skin and flesh, whereas anthocyanin pigments were detected only in peel and showed peaks of

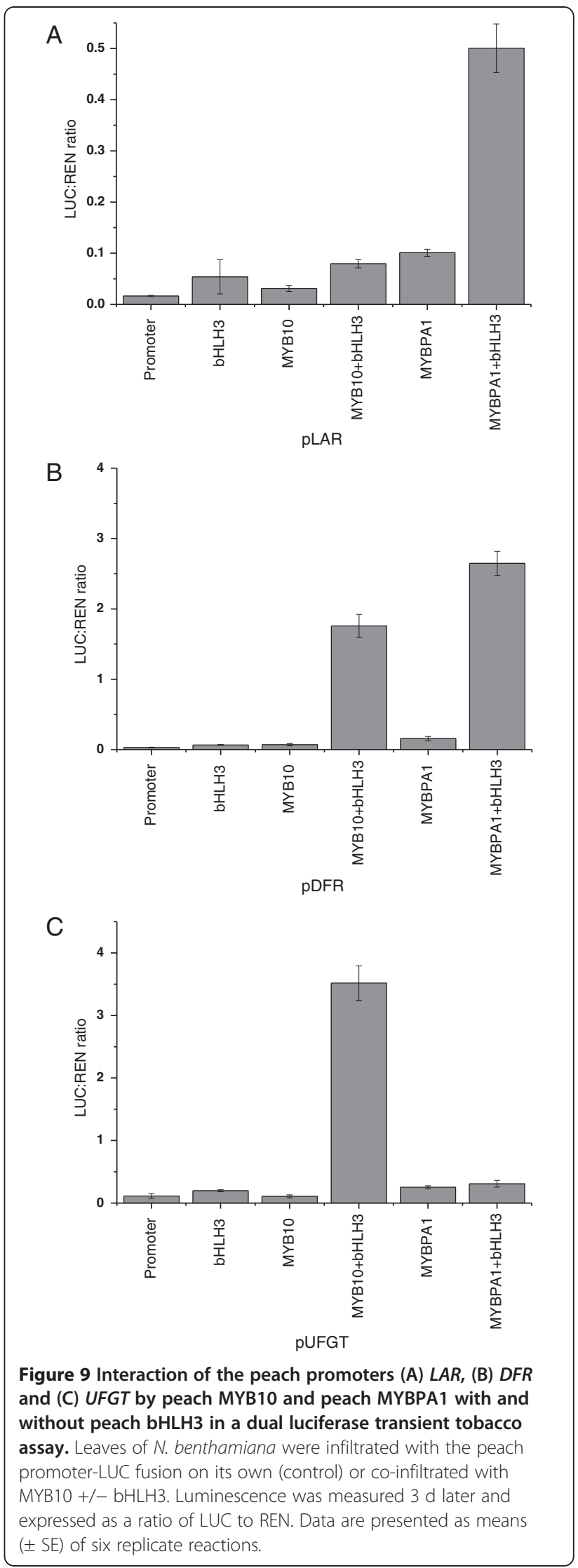




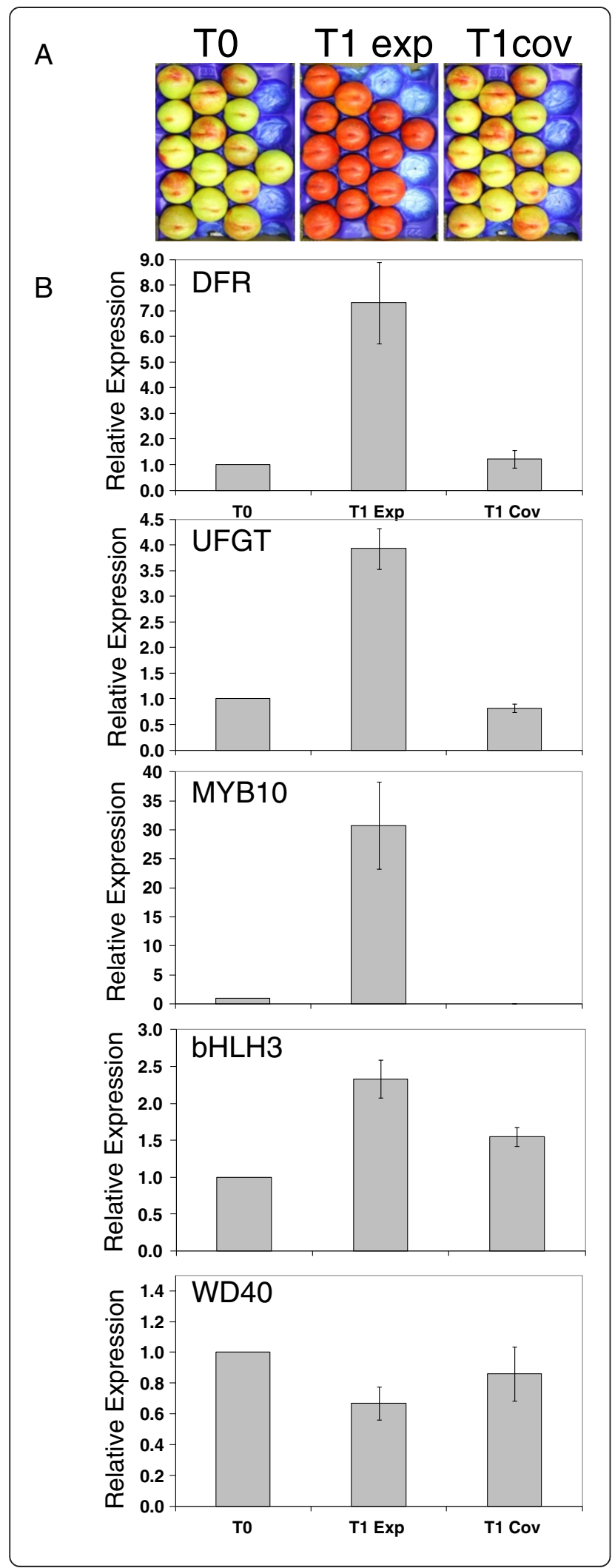

Figure 10 'Stark Red Gold' nectarines harvested from the most shaded parts of the canopy at harvest time (TO) and after 72 hours kept under UV + white light (T1 exp) or in the dark ( $T 1$ cov) (A)., and (B) Expression analyses of the transcripts of DFR, UFGT, MYB10, bHLH3 and WD40 in the peel of the fruit shown in (A). Error bars are the standard error of the mean of three replicate reactions.

biosynthesis at the beginning and end of fruit development (Figure 2B).

A similar profile for the anthocyanin accumulation was observed in the peel of 'Flavortop' nectarines by Tsuda et al., 2004 [48]. In this cultivar anthocyanin accumulation correlated with the transcript levels of four anthocyanin biosynthetic genes (CHI, F3H, ANS, UFGT), assayed by RNA gel-blot analysis. Our qPCR results showed that only the transcript level of the PpUFGT gene showed weak correlation with the accumulation of anthocyanin in fruit peel, whereas all the other flavonoid biosynthetic genes correlated with the concentration of the flavan-3-ols (Figures 3 and 4). FLS expression was correlated well with flavonol profile. These findings suggest that UFGT and FLS in peach fruit might be regulated more specifically than the other flavonoid genes, as observed in grape [31,32].

\section{Transcription factors controlling flavonoid biosynthesis}

Several studies have shown that the expression of the UFGT gene in grape is regulated by the R2R3-MYB TF VvMYBA1, which closely correlates with anthocyanin accumulation in grape skin $[54,60]$. Other biosynthetic genes of the grape flavonoid pathway appear to be regulated by other R2R3-MYB TFs (VvMYBPA1, VvMYBPA2, VvMYB5a and VvMYB5b) which were recently isolated and characterized in grape $[53,55]$. The pattern of expression of the candidate TF genes assayed in developing 'Stark Red Gold' nectarines suggests a tight regulation of UFGT expression, which controls accumulation of anthocyanin in the peel. $L A R$ and $A N R$ may well be regulated by MYBPA1 in peach, while MYB15 and MYB123 are both good candidates for controlling FLS expression (Figure 7). Furthermore, transient expression of these candidate TFs showed that they could directly and differentially regulate promoters of the biosynthetic genes for peach polphenolics (Figure 9). The expression profiles of MYB10, bHLH3 and MYBPA1 are consistent with these TFs regulating anthocyanin and proanthocyanidins in a complex composed of both activators and repressors, as observed in Arabidopsis [43-45].

This regulatory complex, composed of MYB10, bHLH3 and WD40, might control the biosynthesis of the anthocyanin in peach, and the competing presence of MYBPA1 may explain the induction of flavan-3-ols. 
Evidence for this comes from peach flesh, where no MYB10 expression was detected (Figure 6), yet abundant expression of MYBPA1 and all the genes except UFGT is seen (Figures 3 and 7). There is accumulation of flavan-3-ols suggesting a functioning pathway until at least $L D O X$. Peach MYBPA1 was shown to be able to activate the $D F R$ and $L A R$ promoters (Figure 9).
Light-induced anthocyanin accumulation in peach skin is regulated by MYB-bHLH complex

A previous study conducted by Kataoka and Beppu., 2004 [61] showed that anthocyanin accumulation in peach peel was enhanced by UV light. Our expression analyses of the UFGT, MYB10, and bHLH3 genes in the peel of 'Stark Red Gold' nectarines under different light

Table 1 Forward and reverse primers for peach genes used in qPCR analysis of biosynthetic enzymes and candidate transcription factors

\begin{tabular}{|c|c|c|c|}
\hline \multirow[t]{2}{*}{ Gene } & \multirow{2}{*}{$\begin{array}{l}\text { Accession } \\
\text { No./Prunus } \\
\text { gene model }\end{array}$} & \multicolumn{2}{|c|}{ Real time PCR primers ( $5^{\prime}$ to $\left.3^{\prime}\right)$} \\
\hline & & Forward & Reverse \\
\hline \multicolumn{4}{|c|}{ Biosynthetic genes: } \\
\hline \multirow[t]{2}{*}{ CHS } & AB094986 & CAGAGATACCCAAAGGTTGGAAGGC & AACCATCCTTCCCGACAGCGAT \\
\hline & ppa006888m & & \\
\hline \multirow[t]{2}{*}{$\mathrm{CHI}$} & DY634915 & TGAAGACCTCAAGGAACTTCTCAATGG & ACACAGGTGACAACGATACTGCCACT \\
\hline & ppa011276m & & \\
\hline \multirow[t]{2}{*}{$\mathrm{F} 3 \mathrm{H}$} & AB097151 & TCCGAGGGCAGAGCGAAGAAC & TTGTGGAGGCTTGTGAGGATTGG \\
\hline & ppa007636m & & \\
\hline \multirow[t]{2}{*}{ DFR } & AB095030 & GGTCGTCCAGGTGAACATACTGCC & ATTTCTCATGCCATCCATGCCAC \\
\hline & ppa008069m & & \\
\hline \multirow[t]{2}{*}{ LDOX } & EU292219 & AAGTGGGTCACTGCCAAGTGTGTTC & GTGGCTCACAGAAAACTGCCCAT \\
\hline & ppa007738m & & \\
\hline \multirow[t]{2}{*}{ UFGT } & DN676790 & CCGCTGCCTCTCCCAACACTC & CCATCAGCCACATCAAACACCTITAT \\
\hline & ppa005162m & & \\
\hline \multirow[t]{2}{*}{ ANR } & AM288300 & ACTTCAAGGCTAAGGGGCTGCTG & CCAAGCCAGATAAACGCCAATCAC \\
\hline & ppa008295m & & \\
\hline \multirow[t]{2}{*}{$L A R$} & AJ872926 & CATCCACGGGGAAATTCACCTG & ACCCTTCCCAGAGTTACCATCACTGA \\
\hline & ppa007994m & & \\
\hline \multirow[t]{2}{*}{ FLS1 } & GU938685 & GTTTCTGACGGCAACGTTACGAA & CCCAACCCTAGCGATAGGAGCC \\
\hline & ppa008322m & & \\
\hline \multicolumn{4}{|c|}{ Regulators: } \\
\hline \multirow[t]{2}{*}{ MYB10 } & EU155160 & TGATTCCAAGGGTCCACGCTAAAA & CTGGTCTTGGGTTAGATGAAGAACTGC \\
\hline & ppa016711m & & \\
\hline \multirow[t]{2}{*}{ bHLH3 } & DY642427 & TTCCTCTACTAGACGGCGTCGTCG & GGAGGAGGATGGTGGTTGTGGTC \\
\hline & ppa002884m & & \\
\hline \multirow[t]{2}{*}{ WD40 } & ACQ65867 & CCCAGCCTGATACCCCTITGCT & GTCGGCGAACGGATATCCAAAAT \\
\hline & ppa008187m & & \\
\hline \multirow[t]{2}{*}{ MYBPA1 } & CV047374 & GACCCAAGCACCCACAAGAAATTATC & GGCTTTAGTGGCTCCACATGTTGA \\
\hline & ppa009439m & & \\
\hline MYB15 & ppa004560m & GGAAAATTGACACCTTCAGAAGGCC & TCTACCGCCTCTTCGCTTGGAA \\
\hline MYB16 & ppa010277m & AGCTITTGACCAGAGGTATCGACCC & TGCCCAGAAGCCCATTAATAATGC \\
\hline MYB111 & ppa010716m & CGCTTATTGCTGGAAGGTTGCC & GCCTATGGTTATTGGGATCAATGCC \\
\hline MYB123 & ppa023768m & ACTCAACCGTCGACCAACATTGC & TCGGCGTGGTGAGGAAAGATG \\
\hline \multicolumn{4}{|c|}{ Reference gene: } \\
\hline \multirow[t]{2}{*}{ PpActin } & BU045718 & GGAAATTACTGCATTAGCACCCAGC & CCAGATTCATCATACTCGGCTITGG \\
\hline & ppa007214m & & \\
\hline
\end{tabular}


conditions suggest that the regulatory complex described above might be responsive to environmental stimuli (Figure 10).

Flavonol accumulation was not significantly affected by light, although the 72 hour treatment may be too short for this compound class. The accumulation of anthocyanin in the peel of the light-exposed fruit correlated with enhanced transcript levels of all the assayed genes. In particular, the $M Y B 10$ gene was the most strongly responsive to the light, with transcripts not detectable in the fruit kept in the dark and 30-fold more abundant in the lightexposed fruit compared to the fruit at harvest time. These results suggest that anthocyanin biosynthesis was not activated in the fruit kept in the dark because of the absence of MYB10. In the light-exposed fruit, instead, abundant MYB10 might be able to form the protein complex for the induction of the UFGT expression even in the presence of repressors such as MYB111 and MYB16 (Figure 8), as suggested by Matsui et al., (2008) [45] in studies using Arabidopsis. In Arabidopsis the repressor AtMYBL2 is involved in a positive regulatory loop with the bHLH TT8 and R2R3 MYB PAP1 [44,45], so up-regulation of peach $M Y B 111$ by the activation complex may also be occurring.

\section{Conclusions}

The patterns of accumulation of flavonols, flavan-3-ols and anthocyanins in developing 'Stark Red Gold' nectarines suggest that the biosynthesis of these phenolic compounds is differentially regulated in peach/ nectarine fruit. The expression levels of the main flavonoid biosynthetic genes confirmed this hypothesis. The UFGT gene transcript level correlates with anthocyanin accumulation in peach fruit, whereas the patterns of expression of all the other biosynthetic genes correlate with the concentration of flavan-3-ols. These patterns of gene expression might be explained by the involvement of different transcription factors. In particular, we showed that a regulatory complex composed of a MYB, bHLH3 and WD40 controls promoters of polyphenolic biosynthetic steps in peach fruit, activating UFGT (MYB10 and bHLH3) or LAR (MYBPA1 and bHLH3) gene transcription.

The characterization of these transcription factors involved in anthocyanin regulation provides essential information for peach fruit breeding programs with the final aim of selecting new cultivars with improved aesthetical and nutritional properties.

\section{Methods}

Plant material

Yellow-fleshed nectarines cv. 'Stark Red Gold' were collected during the growing season (from May 2008 until August 2008) from an orchard located at the Cadriano
Experimental Station (University of Bologna, Italy; $44^{\circ} 32^{\prime}$ $54.098^{\prime \prime} \mathrm{N}-11^{\circ} 23^{\prime} 13.226 " \mathrm{E}$ ). Peel (including about $1 \mathrm{~mm}$ of the cortical tissue) and flesh samples were collected separately from at least 50 replicate fruit at each of the following developmental stages: S1, 50 days after full bloom (DAFB); S2, 66 DAFB; S2/S3, 74 DAFB; S3, 90 DAFB; S4, 135 DAFB.

For analysis of the effect of light on pigmentation change 45 ripe 'Stark Red Gold' nectarines were harvested at 138 DAFB from the most shaded areas of the tree canopy, to select fruit with a low concentration of anthocyanin. Skin samples were collected from 15 fruit at harvest time (T0). The remaining 30 fruit were transferred to a growth chamber at a constant $25^{\circ} \mathrm{C}$, with UV and white light lamps providing $56 \mu \mathrm{W} / \mathrm{cm}^{2}$ of UVA, $30 \mu \mathrm{W} / \mathrm{cm}^{2}$ of UVB and 7000 lux at fruit surface. Fifteen fruit were completely covered by aluminium foil, whereas the other 15 were exposed to the light. Skin samples were collected after 72 hours from both the fruit exposed to the light (T1 exposed) and those kept in the dark (T1 covered).

At sampling time all the fruit tissues were immediately frozen in liquid nitrogen and stored at $-80^{\circ} \mathrm{C}$ until RNA or phenolic compounds were extracted.

\section{Identification and quantification of anthocyanins, flavonols and flavan-3-ols}

Fruit samples (separated as peel and flesh) were freezedried and ground with pestle and mortar to a fine homogeneous powder. Powder (100 mg dry weight) was then extracted with $1 \mathrm{~mL}$ methanol containing 6-methoxy-flavone (0.025 $\mathrm{mg} \mathrm{mL}^{-1}$ in methanol) as an internal standard. Extractions were performed for $30 \mathrm{~min}$ in an ultrasonic bath, the water being cooled with ice, followed by centrifugation at $12500 \mathrm{~g}$ for $20 \mathrm{~min}$ at $0^{\circ} \mathrm{C}$. The supernatant was then collected and analysed by high-performance liquid chromatography (HPLC).

Samples were analysed by a Waters HPLC system with a Photodiode Array Detector (Waters 2996) and a reversephase Supelcosil $^{\mathrm{TM}}$ LC-18 HPLC column (15 cm long, $4 \mathrm{~mm}$ internal diameter and octadecyl silane particles of $5 \mu \mathrm{m}$ diameter), as described previously [12].

Anthocyanins, flavonols, and flavan-3-ols were identified by comparison of the retention times and UV spectra (between 210 and $560 \mathrm{~nm}$ wavelength) with authentic standards of cyanidin 3-O-glucoside, cyanidin 3-rutinoside, quercetin 3-galactoside, quercetin 3-glucoside, quercetin 3-rutinoside, catechin and epicatechin. Co-chromatography was applied to further confirm initial preliminary identification of chromatographic peaks. Concentrations of anthocyanins and flavan-3-ols, expressed in $\mathrm{mg} \mathrm{g}^{-1}$ dry weight (DW), were calculated from calibration curves obtained with the corresponding external standards. All standards were acquired from Sigma-Aldrich (St Louis, MO, USA). 


\section{Real-Time qPCR expression analysis}

RNA was isolated from the fruit (peel and flesh separately) by a method adapted from that described by Chang et al., (1993) [62]. Following DNaseI treatment using an Ambion DNA-free ${ }^{\mathrm{TM}}$ kit, first-strand cDNA synthesis was carried out on 2 ug of RNA using anchored-oligo $(\mathrm{dT})_{18}$ and random hexamer primers according to the manufacturer's instructions (Transcriptor First Strand cDNA synthesis kit; Roche Diagnostic, Mannheim, Germany).

Genes encoding peach flavonoid pathway enzymes and regulators were selected by homology from the GenBank database and the Genome Database for Peach (http://www. rosaceae.org/species/prunus_persica/genome_v1.0; draft kindly made available by the International Peach Genome Initiative). Gene-specific primers (Table 1) corresponding to these genes were designed using Vector NTI version 9.0.0 (http://www.invitrogen.com) to a stringent set of criteria, enabling application of universal reaction conditions. To check reaction specificity, RT-PCR reactions were carried out according to the manufacturer's instructions (Platinum Taq, Invitrogen, Carlsbad, CA, USA), with a thermal profile as follows: pre-incubation at $95^{\circ} \mathrm{C}$ for $5 \mathrm{~min}$ followed by 35 cycles of $95^{\circ} \mathrm{C}(10 \mathrm{sec}), 56^{\circ} \mathrm{C}(20 \mathrm{sec})$ and $72^{\circ} \mathrm{C}$ (30 sec), with a final extension at $72^{\circ} \mathrm{C}$ for $7 \mathrm{~min}$. The sequences of each primer pair and the relevant accession numbers are shown in Table 1.

qPCR DNA amplification and analysis was carried out using the LightCycler System (Roche LightCycler ${ }^{\circ}$ 480; Roche Diagnostics). All reactions were performed using the LightCycler ${ }^{\circ} 480$ SYBR Green I Master Mix (Roche Diagnostics) according to the procedure described by the manufacturer. Reactions were performed in triplicate using $2.5 \mu \mathrm{l} 2 \times$ Master Mix, $0.25 \mu \mathrm{l}$ each primer $(10 \mu \mathrm{M}), 1.25 \mu \mathrm{l}$ diluted cDNA (1:50) and nuclease-free water (Roche Diagnostics) to a final volume of $5 \mu \mathrm{l}$. A negative water control was included in each run. Fluorescence was measured at the end of each annealing step. Amplification was followed by a melting curve analysis with continual fluorescence data acquisition during the $65-95^{\circ} \mathrm{C}$ melt. The raw data were analysed with the LightCycler software, version 4, and expression was normalized to Prunus persica actin (Actin; BU045718) to minimize variation in cDNA template levels. Actin was selected for normalization due to its consistent transcript level throughout fruit tissues, with crossing threshold (Ct) values changing by $<2$. The skin sample at 50 DAFB (S1) for the developmental series and that at harvest time (T0) for the experiment with artificial light were selected as calibrators with nominal value of 1 . For each gene, a standard curve was generated using a cDNA serial dilution, and the resultant PCR efficiency calculations (ranging between 1.849 and 1.989) were imported into relative expression data analysis. Error bars shown in qPCR data are technical replicates, representing the means $\pm \mathrm{SE}$ of three replicate $\mathrm{qPCR}$ reactions.

\section{Statistical analysis}

Gene expression levels were correlated with anthocyanin, proanthocyanidin and flavonol concentrations over a fruit development series. Pearson correlation ( $r$ ) analysis was performed and tested for statistical significance.

All statistical analysis was carried out using Minitab ${ }^{\circ}$ 16.1.1 statistical software (Minitab, Inc. (2009). Minitab Statistical Software, Release 16 for Windows, State College, Pennsylvania. Minitab ${ }^{\circ}$ is a registered trademark of Mintab, Inc).

\section{Transient expression of candidate transcription factors}

Upstream regions from the ATG start site of the peach genes UFGT (2 kb), DFR (1.6 kb), and LAR (1.4 kb) were isolated from peach gDNA by PCR. These promoter fragments were inserted into the cloning site of pGreen 0800LUC [28,52]. In the same construct, a luciferase gene from Renilla (REN), under the control of a $35 \mathrm{~S}$ promoter, provided an estimate of the extent of transient expression. Activity was expressed as a ratio of LUC to REN activity. The promoter-LUC fusions were used in transient transformation by mixing $100 \mu \mathrm{l}$ of Agrobacterium strain GV3101 (MP90) transformed with the reporter cassette with or without another Agrobacterium culture(s) $(450 \mu \mathrm{l})$ transformed with a cassette containing MYB10, bHLH3 and/or MYBPA1 fused to the $35 \mathrm{~S}$ promoter. The Agrobacterium strains carrying the promoter-LUC fusions and transcription factors were used in transient transformation of Nicotiana benthamiana leaves after co-inoculation and 3 days transient transformation.

\section{Additional files}

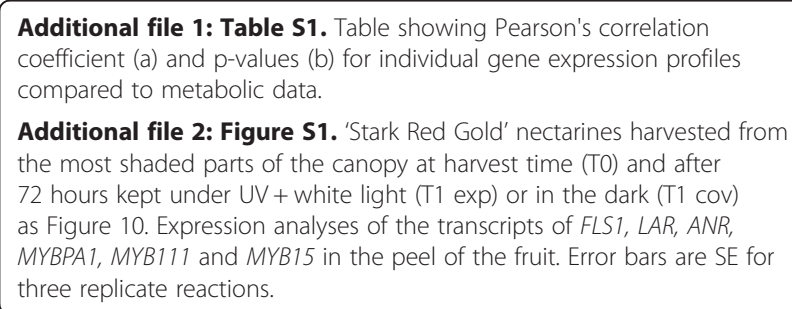

Additional file 2: Figure S1. 'Stark Red Gold' nectarines harvested from the most shaded parts of the canopy at harvest time (TO) and after 72 hours kept under UV + white light (T1 exp) or in the dark (T1 cov) as Figure 10. Expression analyses of the transcripts of FLS1, LAR, ANR, MYBPA1, MYB111 and MYB15 in the peel of the fruit. Error bars are SE for three replicate reactions.

\section{Competing interests}

The authors declare they have no competing interests.

\section{Authors' contributions}

DR conceived of the study, participated in its design, carried out the orchard and molecular biology experiments and drafted the manuscript, ACA and GC conceived of the study, participated in its design and coordination and helped draft the manuscript, RVE and RAH-K carried out DNA and RNA extractions and real-time experiments, CA and VZ carried out flavonoid quantification analysis and edited the manuscript, RPH participated in the design of the study and helped draft the manuscript. All authors read and approved the final manuscript. 


\section{Acknowledgements}

The authors wish to acknowledge funding from the European Commission under the Thematic Priority 5 - Food Quality and Safety of the 6th Framework Programme of RTD ("ISAFRUIT" Project Contract No. FP6-FOOD -CT-2006-016279). The work was also supported by Prin-MIUR funds, project 'Biochemical and Molecular Study of Phenolic Metabolism as Affected by Agronomical and Post-Harvest Techniques in Rosaceous Species', and the New Zealand Foundation for Research Science and Technology C06X0812 'Exploiting Opportunities from Horticultural Genomics'.

\section{Author details}

'Department of Fruit Tree and Woody Plant Sciences, Alma Mater Studiorum, University of Bologna, Viale Fanin 46, 40127, Bologna, Italy. ${ }^{2}$ The New Zealand Institute for Plant and Food Research (PFR), Private Bag 92 169, Auckland, New Zealand. ${ }^{3}$ Faculty of Science and Technology, Free University of Bozen, Piazza Università 5, 39100, Bozen, Italy. ${ }^{4}$ School of Biological Sciences, University of Auckland, Private Bag 92 019, Auckland, New Zealand.

Received: 29 November 2012 Accepted: 12 April 2013

Published: 25 April 2013

\section{References}

1. D'Archivio M, Filesi C, Di Benedetto R, Gargiulo R, Giovannini C, Masella R: Polyphenols, dietary sources and bioavailability. Ann Ist Super Sanita 2007, 43(4):348-361.

2. Tsao R, Yang R, Young JC, Zhu H: Polyphenolic profiles in eight apple cultivars using high-performance liquid chromatography (HPLC). J Agric Food Chem 2003, 51(21):6347-6353.

3. Vinson JA, Su XH, Zubik L, Bose P: Phenol antioxidant quantity and quality in foods: Fruits. J Agric Food Chem 2001, 49(11):5315-5321.

4. Forkner RE, Marquis RJ, Lill JT: Feeny revisited: condensed tannins as anti-herbivore defences in leaf-chewing herbivore communities of Quercus. Ecol Entomol 2004, 29(2):174-187.

5. Wrangham RW, Conklin-Brittain NL, Hunt KD: Dietary response of chimpanzees and cercopithecines to seasonal variation in fruit abundance. I. Antifeedants. Int J Primatol 1998, 19(6):949-970.

6. Boyer J, Liu RH: Apple phytochemicals and their health benefits. Nutr J 2004, 3:5.

7. Hagiwara A, Miyashita K, Nakanishi T, Sano M, Tamano S, Kadota T, Koda T, Nakamura M, Imaida K, Ito N, et al: Pronounced inhibition by a natural anthocyanin, purple corn color, of 2-amino-1-methyl-6-phenylimidazo [4,5-b]pyridine (PhIP)-associated colorectal carcinogenesis in male F344 rats pretreated with 1,2-dimethylhydrazine. Cancer Lett 2001, 171(1):17-25.

8. Kroon P. Williamson G: Polyphenols: dietary components with established benefits to health? J Sci Food Agric 2005, 85(8):1239-1240.

9. Butelli E, Titta L, Giorgio M, Mock HP, Matros A, Peterek S, Schijlen EG, Hall $R D$, Bovy AG, Luo J, et al: Enrichment of tomato fruit with healthpromoting anthocyanins by expression of select transcription factors. Nat Biotechnol 2008, 26(11):1301-1308.

10. Galvano F, La Fauci L, Vitaglione P, Fogliano V, Vanella L, Felgines C: Bioavailability, antioxidant and biological properties of the natural freeradical scavengers cyanidin and related glycosides. Ann Ist Super Sanita 2007, 43(4):382-393.

11. Singh M, Arseneault M, Sanderson T, Murthy V, Ramassamy C: Challenges for research on polyphenols from foods in Alzheimer's disease: bioavailability, metabolism, and cellular and molecular mechanisms. J Agric Food Chem 2008, 56(13):4855-4873.

12. Andreotti C, Ravaglia D, Ragaini A, Costa G: Phenolic compounds in peach (Prunus persica) cultivars at harvest and during fruit maturation. Ann Appl Biol 2008, 153(1):11-23.

13. Tomas-Barberan FA, Gil MI, Cremin P, Waterhouse AL, Hess-Pierce B, Kader AA: HPLC-DAD-ESIMS analysis of phenolic compounds in nectarines, peaches, and plums. J Agric Food Chem 2001, 49(10):4748-4760.

14. Schijlen EGW, de Vos CHR, van Tunen AJ, Bovy AG: Modification of flavonoid biosynthesis in crop plants. Phytochemistry 2004, 65(19):2631-2648.

15. Winkel-Shirley B: Flavonoid biosynthesis. A colorful model for genetics, biochemistry, cell biology, and biotechnology. Plant Physiol 2001, 126(2):485-493.

16. Allan AC, Hellens RP, Laing WA: MYB transcription factors that colour our fruit. Trends Plant Sci 2008, 13(3):99-102.

17. Davies KM, Schwinn KE: Transcriptional regulation of secondary metabolism. Funct Plant Biol 2003, 30(9):913-925.
18. Koes R, Verweij W, Quattrocchio F: Flavonoids: a colorful model for the regulation and evolution of biochemical pathways. Trends Plant Sci 2005 10(5):236-242

19. Niu SS, Xu CJ, Zhang WS, Zhang B, Li X, Lin-Wang K, Ferguson IB, Allan AC, Chen KS: Coordinated regulation of anthocyanin biosynthesis in Chinese bayberry (Myrica rubra) fruit by a R2R3 MYB transcription factor. Planta 2010, 231(4):887-899.

20. Palapol Y, Ketsa S, Lin-Wang K, Ferguson IB, Allan AC: A MYB transcription factor regulates anthocyanin biosynthesis in mangosteen (Garcinia mangostana L.) fruit during ripening. Planta 2009, 229(6):1323-1334.

21. Dare AP, Schaffer RJ, Lin-Wang K, Allan AC, Hellens RP: Identification of a cis-regulatory element by transient analysis of co-ordinately regulated genes. Plant Methods 2008, 4:17.

22. Hartmann U, Sagasser M, Mehrtens F, Stracke R, Weisshaar B: Differential combinatorial interactions of cis-acting elements recognized by R2R3-MYB, BZIP, and BHLH factors control light-responsive and tissue-specific activation of phenylpropanoid biosynthesis genes. Plant Mol Biol 2005, 57(2):155-171.

23. Hernandez JM, Heine GF, Irani NG, Feller A, Kim MG, Matulnik T, Chandler VL, Grotewold E: Different mechanisms participate in the R-dependent activity of the R2R3 MYB transcription factor C1. J Biol Chem 2004, 279(46):48205-48213.

24. Honda C, Kotoda N, Wada M, Kondo S, Kobayashi S, Soejima J, Zhang ZL, Tsuda T, Moriguchi T: Anthocyanin biosynthetic genes are coordinately expressed during red coloration in apple skin. Plant Physiol Biochem 2002, 40(11):955-962.

25. Kondo S, Hiraoka K, Kobayashi S, Honda C, Terahara N: Changes in the expression of anthocyanin biosynthetic genes during apple development. J Am Soc Hort Sci 2002, 127(6):971-976.

26. Takos AM, Robinson SP, Walker AR: Transcriptional regulation of the flavonoid pathway in the skin of dark-grown 'Cripps' Red' apples in response to sunlight. J Horticult Sci Biotechnol 2006, 81(4):735-744.

27. Ban $Y$, Honda $C$, Hatsuyama $Y$, Igarashi $M$, Bessho H, Moriguchi T: Isolation and functional analysis of a MYB transcription factor gene that is a key regulator for the development of red coloration in apple skin. Plant Cell Physiol 2007, 48(7):958-970.

28. Espley RV, Brendolise C, Chagne D, Kutty-Amma S, Green S, Volz R, Putterill J, Schouten HJ, Gardiner SE, Hellens RP, et al: Multiple Repeats of a Promoter Segment Causes Transcription Factor Autoregulation in Red Apples. Plant Cell 2009, 21(1):168-183.

29. Espley RV, Hellens RP, Putterill J, Stevenson DE, Kutty-Amma S, Allan AC: Red colouration in apple fruit is due to the activity of the MYB transcription factor, MdMYB10. Plant J 2007, 49(3):414-427.

30. Takos AM, Jaffe FW, Jacob SR, Bogs J, Robinson SP, Walker AR: Lightinduced expression of a MYB gene regulates anthocyanin biosynthesis in red apples. Plant Physiol 2006, 142(3):1216-1232.

31. Boss PK, Davies C, Robinson SP: Analysis of the Expression of Anthocyanin Pathway Genes in Developing Vitis vinifera L. cv Shiraz Grape Berries and the Implications for Pathway Regulation. Plant Physiol 1996, 111(4):1059-1066.

32. Kobayashi S, Ishimaru M, Hiraoka K, Honda C: Myb-related genes of the Kyoho grape (Vitis labruscana) regulate anthocyanin biosynthesis. Planta 2002, 215(6):924-933.

33. Lin-Wang K, Bolitho K, Grafton K, Kortstee A, Karunairetnam S, McGhie TK, Espley RV, Hellens RP, Allan AC: An R2R3 MYB transcription factor associated with regulation of the anthocyanin biosynthetic pathway in Rosaceae. BMC Plant Biol 2010, 10:50.

34. Mehrtens F, Kranz H, Bednarek P, Weisshaar B: The Arabidopsis transcription factor MYB12 is a flavonol-specific regulator of phenylpropanoid biosynthesis. Plant Physio/ 2005, 138(2):1083-1096.

35. Stracke R, Ishihara H, Huep G, Barsch A, Mehrtens F, Niehaus K, Weisshaar B: Differential regulation of closely related R2R3-MYB transcription factors controls flavonol accumulation in different parts of the Arabidopsis thaliana seedling. Plant J 2007, 50(4):660-677.

36. Ferreyra ML, Rius S, Emiliani J, Pourcel L, Feller A, Morohashi K, Casati P, Grotewold E: Cloning and characterization of a UV-B-inducible maize flavonol synthase. Plant J 2010, 62(1):77-91

37. Czemmel S, Stracke R, Weisshaar B, Cordon N, Harris NN, Walker AR, Robinson SP, Bogs J: The Grapevine R2R3-MYB Transcription Factor VvMYBF1 Regulates Flavonol Synthesis in Developing Grape Berries. Plant Physiol 2009, 151(3):1513-1530.

38. Bogs J, Downey MO, Harvey JS, Ashton AR, Tanner GJ, Robinson SP: Proanthocyanidin synthesis and expression of genes encoding 
leucoanthocyanidin reductase and anthocyanidin reductase in developing grape berries and grapevine leaves. Plant Physiol 2005, 139(2):652-663.

39. Takos AM, Ubi BE, Robinson SP, Walker AR: Condensed tannin biosynthesis genes are regulated separately from other flavonoid biosynthesis genes in apple fruit skin. Plant Sci 2006, 170(3):487-499.

40. Henry-Kirk RA, McGhie TK, Andre CM, Hellens RP, Allan AC: Transcriptional analysis of apple fruit proanthocyanidin biosynthesis. J Exp Bot 2012, 63(15):5437-5450.

41. Terrier N, Torregrosa L, Ageorges A, Vialet S, Verries C, Cheynier V, Romieu C: Ectopic Expression of VvMybPA2 Promotes Proanthocyanidin Biosynthesis in Grapevine and Suggests Additional Targets in the Pathway. Plant Physiol 2009, 149(2):1028-1041.

42. Aharoni A, De Vos CH, Wein M, Sun Z, Greco R, Kroon A, Mol JN, O'Connell AP: The strawberry FaMYB1 transcription factor suppresses anthocyanin and flavonol accumulation in transgenic tobacco. Plant $J$ 2001, 28(3):319-332

43. Rowan DD, Cao M, Lin-Wang K, Cooney JM, Jensen DJ, Austin PT, Hunt MB, Norling C, Hellens RP, Schaffer R, et al: Environmental regulation of leaf colour in red 35S:PAP1 Arabidopsis thaliana. New Phytol 2009, 182(1):102-115.

44. Dubos C, Le Gourrierec J, Baudry A, Huep G, Lanet E, Debeaujon I, Routaboul JM, Alboresi A, Weisshaar B, Lepiniec L: MYBL2 is a new regulator of flavonoid biosynthesis in Arabidopsis thaliana. Plant J 2008, 55(6):940-953.

45. Matsui K, Umemura Y, Ohme-Takagi M: AtMYBL2, a protein with a single MYB domain, acts as a negative regulator of anthocyanin biosynthesis in Arabidopsis. Plant J 2008, 55(6):954-967.

46. Lin-Wang K, Micheletti D, Palmer J, Volz R, Lozano L, Espley R, Hellens RP, Chagne D, Rowan DD, Troggio $M$, et al: High temperature reduces apple fruit colour via modulation of the anthocyanin regulatory complex. Plant Cell Environ 2011, 34(7):1176-1190.

47. Ogundiwin EA, Peace CP, Nicolet CM, Rashbrook VK, Gradziel TM, Bliss FA, Parfitt D, Crisosto CH: Leucoanthocyanidin dioxygenase gene (PpLDOX): a potential functional marker for cold storage browning in peach. Tree Genet Genom 2008, 4(3):543-554.

48. Tsuda T, Yamaguchi M, Honda C, Moriguchi T: Expression of anthocyanin biosynthesis genes in the skin of peach and nectarine fruit. J Am SOC Hort Sci 2004, 129(6):857-862.

49. Beckman TG, Alcazar JR, Sherman WB, Werner DJ: Evidence for qualitative suppression of red skin color in peach. Hortscience 2005, 40(3):523-524.

50. Beckman TG, Sherman WB: Probable qualitative inheritance of full red skin color in peach. HortScience 2003, 38(6):1184-1185.

51. Kumar S, Tamura K, Nei M: MEGA3: Integrated software for Molecular Evolutionary Genetics Analysis and sequence alignment. Brief Bioinform 2004, 5(2):150-163.

52. Hellens RP, Allan AC, Friel EN, Bolitho K, Grafton K, Templeton MD, Karunairetnam S, Gleave AP, Laing WA: Transient expression vectors for functional genomics, quantification of promoter activity and RNA silencing in plants. Plant Methods 2005, 1:13.

53. Deluc L, Barrieu F, Marchive C, Lauvergeat V, Decendit A, Richard T, Carde JP, Merillon JM, Hamdi S: Characterization of a grapevine R2R3-MYB transcription factor that regulates the phenylpropanoid pathway. Plant Physiol 2006, 140(2):499-511.

54. Kobayashi S, Yamamoto NG, Hirochika H: Association of VvmybA1 gene expression with anthocyanin production in grape (Vitis vinifera) skin color mutants. J Jpn Soc Hortic Sci 2005, 74(3):196-203.

55. Bogs J, Jaffe FW, Takos AM, Walker AR, Robinson SP: The grapevine transcription factor VVMYBPA1 regulates proanthocyanidin synthesis during fruit development. Plant Physiol 2007, 143(3):1347-1361.

56. Matus JT, Poupin MJ, Canon P, Bordeu E, Alcalde JA, Arce-Johnson P: Isolation of WDR and bHLH genes related to flavonoid synthesis in grapevine (Vitis vinifera L.). Plant Mol Biol 2010, 72(6):607-620.

57. Mathews H, Clendennen SK, Caldwell CG, Liu XL, Connors K, Matheis N, Schuster DK, Menasco DJ, Wagoner W, Lightner J, et al: Activation tagging in tomato identifies a transcriptional regulator of anthocyanin biosynthesis, modification, and transport. Plant Cell 2003, 15(8):1689-1703.

58. Sapir M, Oren-Shamir M, Ovadia R, Reuveni M, Evenor D, Tadmor Y, Nahon S, Shlomo H, Chen L, Meir A, et al: Molecular aspects of Anthocyanin fruit tomato in relation to high pigment-1. J Hered 2008, 99(3):292-303.

59. Borovsky Y, Oren-Shamir M, Ovadia R, De Jong W, Paran I: The A locus that controls anthocyanin accumulation in pepper encodes a MYB transcription factor homologous to Anthocyanin2 of Petunia. Theor Appl Genet 2004, 109(1):23-29.
60. Walker AR, Lee E, Bogs J, McDavid DAJ, Thomas MR, Robinson SP: White grapes arose through the mutation of two similar and adjacent regulatory genes. Plant J 2007, 49(5):772-785.

61. Kataoka I, Beppu K: UV irradiance increases development of red skin color and anthocyanins in 'Hakuho' peach. Hort Science 2004, 39(6):1234-1237.

62. Chang S, Puryear J, Cairney J: A simple and efficient method for isolating RNA from pine trees. Plant Mol Biol Rep 1993, 11:113-116.

doi:10.1186/1471-2229-13-68

Cite this article as: Ravaglia et al:: Transcriptional regulation of flavonoid biosynthesis in nectarine (Prunus persica) by a set of R2R3 MYB transcription factors. BMC Plant Biology 2013 13:68.

\section{Submit your next manuscript to BioMed Central and take full advantage of:}

- Convenient online submission

- Thorough peer review

- No space constraints or color figure charges

- Immediate publication on acceptance

- Inclusion in PubMed, CAS, Scopus and Google Scholar

- Research which is freely available for redistribution

Submit your manuscript at www.biomedcentral.com/submit
C) Biomed Central 